\title{
Ortopedi ve Travmatoloji uzmanlık alanına giren tıbbi uygulama hatalarına (malpraktis) ilişkin Adli Tıp deneyimlerimiz
}

\section{Forensic Medicine experiences related to malpractice in Orthopedics and Traumatology}

\author{
Mehmet Akif Kaygusuz ${ }^{1}$, Sevda Uzun Dırvar ${ }^{2}$
}

${ }^{1}$ S.B. İstanbul Metin Sabancı Baltalimanı Kemik Hastalıkları Eğitim ve Araştırma Hastanesi, Ortopedi ve Travmatoloji Kliniği, İstanbul ${ }^{2}$ S.B. İstanbul Metin Sabancı Baltalimanı Kemik Hastalıkları Ĕğitim ve Araştırma Hastanesi, Sağlık Yönetimi Doktora Öğrencisi, İstanbul

2016-2019 yılları arası Adli Tıp Kayıtları incelendiğinde Ortopedi ve Travmatoloji alanında yoğunlaşan şikayetlerin alçı uygulamalarından el kesilerine; ekstremite, pelvis ve omurga kırıklarının takip ve tedavisinden ortopedik elektif cerrahi girişimlere kadar uzanan bir yelpazede çeşitlilik arz ettiği görülmektedir. Ortopedi ve Travmatoloji alanını ilgilendiren cerrahi girişimlerde adli dava dosyaları genellikle damar ve sinir yaralanmaları, aşırı kan kaybına neden olan kırıklar, alçı uygulamalarına bağlı sorunlar, el ve ekstremite kesiklerinin ve yabancı cisim retansiyonlarının tanı ve yönetimi, artroskopik girişimler ile ilgili problemler, omurga kırıkları ve yaralanmaları, kırık tespiti ve eklem protezi uygulamaları ile ilgili şikayetler, komplikasyonlar ve komplikasyon yönetimi konularında yoğunlaşma göstermektedir. Ortopedi ve travmatoji uzmanlarının tedavi süreçlerinin bizzat içerisinde olması, alçı takibini ciddiyetle yapması, hastayı multidisipliner yönetmesi ve gerekli konsültasyonları istemesi gerekmektedir.

Anahtar sözcülkler: malpraktis, adli tıp, ortopedi ve travmatoloji

659 sayılı Kanunu'na göre; Adli Tıp Kurumu, adalet işlerinde bilirkişilik yapmakla görevlendirilmiştir. Adlî Tıp Genel Kurulu, Adlî Tıp Kurumu Başkanı'nın başkanlığında, Adlî Tıp ìhtisas Kurulları başkan ve üyelerinden oluşur. Mesleki kusurlara 7.ve 8.üst kurul bakmaktadır. Bunlardan 8.üst kurul ölümle sonuçlanan dosyalara, 7.üst kurul ise ölümlü olmayan tıbbi kusur dosyalarına bakmaktadır. Bu Kurullar, bir başkan ve adlî tıp uzmanı iki üye ile birer Ortopedi ve Travmatoloji, Radyoloji, Göz Hastalıkları, Kulak Burun Boğaz Hastalıkları, Genel Cerrahi, Göğüs Cerrahisi, Kalp ve Damar Cerrahisi, Plastik, Rekonstrüktif ve Estetik Cerrahi, Nöroloji, Kadın Hastalıkları ve Doğum, Enfeksiyon Hastalıkları
Forensic Medicine Records complaints concentrated in the field of orthopedics and traumatology were examined between 2016-2019, It is seen that there is a wide range of complaints from plas-ter applications to hand cuts; extremity, pelvic and spine fractures treatment and follow-up and orthopedic elective surgery. Forensic case files in orthopedic surgery are usually vascular and nerve injuries, fractures that cause excessive blood loss, problems related to plaster applications, diagnosis and management of hand and limb cuts and foreign body retention, problems with arthroscopic procedures, fractures and injuries of the spine, fracture fixation and joint prosthesis complaints, complications, and complication management. Orthopaedics and traumatology specialist should be involved in the treatment process personally, follow the plaster cast seriously, manage the patient multidisciplinary and ask for the necessary consultations.

Key words: malpractice, forensic medicine, orthopaedics and traumatology

- İletişim adresi: Prof. Dr. Mehmet Akif Kaygusuz, S.B. İstanbul Metin Sabancı Baltalimanı Kemik Hastalıkları Eğitim ve Araştırma Hastanesi, Ortopedi ve Travmatoloji Kliniği, İstanbul Tel: 0532 - 5231383 e-posta: makifkaygusuz@gmail.com

- Geliș tarihi: 13 Aralık 2019 Kabul tarihi: 19 Aralık 2019

Uzmanlarından oluşmaktadır.[1] Hekimlik Meslek Etiği Kuralları'nın 13. maddesinde; hekimliğin kötü uygulanması (malpraktis) belirtilmiş, madde içeriğinde ise bilgisizlik, deneyimsizlik ya da ilgisizlik nedeniyle hastanın zarar görmesi şeklinde açıklama yapılmıştır. ${ }^{[2]}$

Ülkemizde sağlık hizmetlerinin yaygınlaşması ve sosyokültürel yapıdaki değişmeler ister istemez hasta-hastane ve hasta-hekim arasındaki ilişkileri, iletişimi ve davranışı etkilemiştir. Özellikle 2000'li yıllardan itibaren hastalar hekimleri ve hizmet aldıkları sağlık kurumlarını daha fazla sorgular hale gelmişlerdir ve daha önceleri çok rastlamadığımız bu durumlar giderek artmaktadır. 
2016-2019 yılları arası üç yıllık Adli Tıp Kurumu Kayıtları incelendiğinde Ortopedi ve Travmatoloji alanında yoğunlaşan şikayetlerin alçı uygulamalarından el kesilerine; ekstremite, pelvis ve omurga kırıklarının takip ve tedavisinden ortopedik elektif cerrahi girişimlere kadar uzanan bir yelpazede çeşitlilik arz ettiği görülmektedir. Hastaların şikâyetleri teşhiste yanlışlık olduğu iddiaları ile olabildiği gibi uygulanan tedavinin iyileştirici etkisinin olmaması ve/ veya yanlış tedavi yapıldığı iddiası ile de olabilmektedir. Hastaların şikâyetlerinin büyük bir kısmında yapılan teşhis ve uygulanan tedavinin eksik ve yanlış olduğuna dair kanaat belirten başka bir hekimin yorumlarının büyük etkisinin olduğu gözlenmektedir. Açılan davaların çoğunda genellikle hastane ve hekim kusur (malpraktis) yönünden itham edilmekte ve kusur olup olmadığı sorulmaktadır. Hukuki süreç maddi delille anlam kazandığından, karar aşamasında verilen ifadeler kadar dosya içeriğindeki tıbbi kayıtlar ve belgeler de çok önem kazanmaktadır. Bu nedenle teşhis ve tedavi süreçlerinin kayıtlarının yeterli şekilde muhafaza edilmesi oldukça önemlidir. Hekim doğru hastaya doğru teşhisi ve tedaviyi uluslararası rehberlere uygun olarak, güncel ve modern teşhis ve tedavi metodolojisini kullanarak yaptı̆̆ını kayıt altına almalıdır. Eğer hekim bu ölçülerde bir teşhis ve tedavi sürecini yönetmişse, ayrıca tedavi sürecinde çıkan komplikasyonları da bu prensipler dâhilinde çözmüşse veya çözmeye çalışmışsa mesleğinin gereğini yerine getirmiş olmaktadır.

Ortopedi ve Travmatoloji branş alanındaki cerrahi uygulamalarda adli dava dosyaları genellikle belli konularda yoğunlaşma göstermektedir. Bunlar;

- Damar ve sinir yaralanmaları,

- Aşırı kan kaybına neden olan kırıklar,

- Alçı uygulamalarına bağlı sorunlar,

- El ve ekstremite kesiklerinin ve yabancı cisim retansiyonlarının tanı ve yönetimi,

- Artroskopik girişimler ile ilgili problemler,

- Omurga kırıkları ve yaralanmaları,

- Kırık tespiti ve eklem protezi uygulamaları ile ilgili şikayetler,

- Komplikasyonlar ve komplikasyon yönetimidir.

Bu başlıklara geçmeden önce bilinmesi gerekir ki; bir hekim bir hastayı muayene etmeye başladıktan itibaren, tedavi sürecini tamamlayana kadar bazı yükümlülüklerin altına girmektedir. Bu yükümlülükler;

1. Klinik muayeneyi yapmak ve kayıt etmek.

2. Gerekli laboratuvar testlerini yaptırmak.
3. Teşhis kesinleştikten sonra hastaya yapılacak tedaviyi teklif etmek, tedavinin faydalarını ve komplikasyonlarını anlatarak alternatif tedavilerden de bahsederek hastanın onayını ve onamını almak.

\section{Evrensel kabul edilen tedaviyi uygulamak.}

Hekim bu süreçlerde modern tıp biliminin belirlediği araç ve yöntemleri kullanmak durumundadır. Bu süreçlerde bir eksiklik, bir yanlışlık, bir hata olduğu takdirde hasta-hekim ilişkisi bozulabilmekte ve adli davalara şikâyet konusu olabilmektedir. Hekimler tedavi sürecini eksiksiz ve doğru bir şekilde tamamladıkları takdirde süreç tamamen bitmiş olmamaktadır. Tedavi ve takip süreçlerinde ortaya çıkan komplikasyonlar aslında tedavinin devamı gibi kabul edilebilir. Bu nedenle hekimler komplikasyon yönetimini yine uluslararası rehberler ve uluslararası standartlar çerçevesinde yapmak durumundadırlar. Komplikasyonun iyi yönetilmemesi durumu kusura (malpraktise) dönüşebilmektedir. Bir komplikasyonun ne zaman ve hangi durumlarda kusur olduğu ülkelerin sağlık hukuku ve bununla ilgili oluşturulan kurullar tarafından bazen farklı tanımlanabilmektedir. Ülkelerin sağlık standartları yükseldikçe sağlık hukuku tarafından komplikasyon olarak tanımlanan bir süreç veya patoloji bir süre sonra malpraktis kavramı içinde değerlendirilebilir. Örneğin, bizim adli hukukumuzda cerrahi tedavi esnasında gelişen bir sinir hasarı komplikasyon olarak değerlendirilebilirken, Avrupa veya Amerika Birleşik Devletleri sağlık hukuku sisteminde malpraktis olarak tanımlanabilir.

\section{Ortopedi ve Travmatoloji Pratiğinde En Sık Rastlanan Problemlerle İlgili Örnekler}

\section{Damar ve sinir yaralanmaları}

Dava dosyalarından elde ettiğimiz tecrübelerimize göre; genellikle Ortopedi ve Travmatoloji uzmanlarımız ekstremite kırıkları ile beraber olan damar ve sinir yaralanmalarının hem teşhisinde hem de yönetiminde zorlanmakta ve bu konuda ciddi şekilde adli davalara konu olmaktadırlar. Dosya içeriklerinden gördüğümüz kadarıyla, hekimler kırık ekstremitede damar ve sinir muayenesi yaptıklarına dair hiçbir bilgiyi ve kaydı hasta dosyasına işlememekte ve hastanın sağlık kurumuna başvurduğu tarihteki kayıtlar incelendiğinde genellikle hekimlerin damar sinir lezyonu olup olmadığına dair bir kayıt ve bildirimde bulunmadıkları görülmektedir. Bu durumda hasta geldiği anda olmuş olan veya sonradan gelişen bir damar sinir yaralanması hekime kusur olarak yansımaktadır. Halbuki Ortopedi ve Travmatoloji uzmanı damar ve sinir yaralanmasını mutlak tedavi etmekle yükümlü değildir. Teşhis edip veya şüphelendiği takdirde 
gerekli konsültasyonları yapıp kayıt altına aldığı takdirde sorumluluktan kurtulacaktır. Adli dava dosyaları içinde, bu şekilde tanımlanmamış veya ameliyat sırasında gelişip geç fark edilen bu nedenle ekstremite kaybı ile sonuçlanan azımsanmayacak sayıda dosya mevcuttur. Sinir yaralanmalarında ise sinir tamiri geç de yapılabileceğinden, en azından kırığa müdahale eden Ortopedi ve Travmatoloji uzmanının muayene ettiğini, muayene esnasında hastanın koopere olup olmadığını ve yeniden muayenesinin gerektiğini belirten bir kayıdın bulunması halinde, hekimin görevini yaptığı ve kusura yol açacak bir eylem bulunmadığı sonucu çıkacaktır.

Örnek Olgu 1: Otuz altı yaşında erkek hasta, motosiklet kazası sonucu tibia kırı̆ıı, subtotal ampütasyon (diz altı) nedeniyle büyük bir kentimizin eğitim ve araştırma hastanesine getirilir. Hastayı Ortopedi ve Travmatoloji ile kalp damar cerrahisi uzmanı görür. Kalp damar cerrahisi uzmanı sevkini ister ancak dosyada sevk gerekçesinin belirtilmediği tespit edilir; muhtemelen replantasyon yapılan bir merkeze sevki kastedilmektedir. Hasta sevk için beklerken exitus (ölüm) olur. Bu olguda;

- İlgili hastanenin kalp damar cerrahisi uzmanı aktif olarak bulunmaktadır. Ancak muayene dışında vakayı üstlenmemiştir.

- Hastane üst düzey bir hastanedir. Sevk edilmesi uygun değildir.

- Sevk kararı yanlışıkla bile verilmiş olsa sevk için bekleyen hastanın durumu stabil hale getirilmelidir. Ne yazık ki bunların hiçbiri yapılmamıştır.

Örnek Olgu 2: Kırk iki yaşında erkek hasta fibula kırığı teşhisi ile bir üniversite hastanesi Ortopedi ve Travmatoloji Kliniğine yatırılır. Yatırıldığı anda hastanın dizinde ve bacağında şişlik, ekstremite çapında artma mevcuttur. Hastanın tansiyonunda 2-3 saat sonra düşme olur. Nöbetçi Ortopedi ve Travmatoloji asistan hekimi hemoglobin ve hematokritteki düşmeyi ve tansiyondaki düşüklüğü whatsapp görüntüsü ve telefonla icap nöbetçisi Ortopedi ve Travmatoloji uzmanına iletir. Uzman tarafindan "takip edin kan transfüzyonuna gerek yok" denir. Altı saat sonra hasta exitus (ölüm) olur. Exitus nedeni popliteal arter yaralanması ve buna bağlı kanamadır. Muhtemelen hastada diz çıkığı olmuş, hastaneye geldiğinde çıkık redükte olmuştur. Bu olguda;

- Hematokrit, hemoglobin ve tansiyon düşüklüğü ile seyreden hasta bizzat uzman tarafindan görülmeli ve takibi sık aralıklarla yapılmalıydı.

- Daha önemlisi her türlü ekstremite yaralanmasında, vasküler muayene ve izlem mutlaka yapılması gereken bir işlemdir.

\section{Aşırı kan kaybına neden olan kırıklar}

Ne yazık ki pelvis kırıkları acil tıbbımızın ciddi bir kara deliğidir. Adli Tıp'ta pelvis kırığı nedeniyle hastanelerin aciline müracaat edip saatler içinde hipovolemi nedeniyle exitus olan azımsanmayacak sayıda olgu vardır. 6-9 ünite kan transfüzyonu ve geçici tespit ile stabil hale gelebilecek bir çok hasta, adli dosyalara giren otopsi raporlarında büyük damar yaralanması olmadan kaybedilmektedir. Burada yine maalesef acil tıp uzmanı (varsa eğer), genel cerrahi uzmanı, ortopedi ve tavmatoloji uzmanı ile üroloji uzmanı arasında hastalar sahipsiz kalmakta ve sonuçta bir exitus olayında her üçü de kusurlu duruma düşmektedir. Bu nedenle pelvis kırıkları ve yönetimi bir Ortopedi ve Travmatoloji uzmanı tarafından çok iyi bilinmeli, mutlaka bu tür hastalar yatırılarak yoğun bakım şartlarında takip edilmeli, yeterli kan ve sıvı transfüzyonu yapılmalı, basit bir hamak veya pelvik bandajlama ile müdahale edilmelidir. Adli dosyalarda genellikle bu süreçlerin bazı hekimler tarafından yapılmadığı ve hastaların acile müracaatlarından 6-8 saat sonra ani tansiyon düşmesi ile kaybedildikleri gözlenmektedir. Hâlbuki hastaların yukarıda bahsettiğimiz şekilde temel bazı uygulamalarla müdahalesi hem hayat kurtarıcıdır hem de hekimi açılacak bir malpraktis davasından koruyacaktır.

Örnek Olgu 1: Otuz iki yaşında genç erkek hasta, göçük altında kalma sonucu bir üniversite hastanesinin acil servisine müracaat eder. Hastanın geldiği anda vital bulguları stabildir. Genel cerrahi, Ortopedi ve Travmatoloji ile üroloji konsültasyonları yapılır. Instabl bir pelvis kırığı şüphesi mevcut. Ürolojik muayenede üretradan kanama tespit edilir. Ortopedi ve Travmatoloji uzmanı, üroloji uzmanı tarafindan yatırılmasını, üroloji uzmanı ise Ortopedi ve Travmatoloji uzmanı tarafından yatırılmasını talep eder. Hasta acil müşahedede iken sekiz saat sonra hipovolemiden exitus olur. Bu olguda;

- Hastanın mutlaka bu iki hekimden birisi tarafindan yatırılması ve stabil hale getirildikten sonra esas tedavisinin yapılması gerektiğinden bunları yapmayan hem Ortopedi ve Travmatoloji hem de üroloji uzmanı hatalı davranmıştır.

- Acil serviste müşahede altındaki hastayı stabil hale getirmekle görevli acildeki uzmanlar gereken tıbbi takip ve özeni göstermemişlerdir.

Örnek Olgu 2: Altmış yaşında bayan hasta, trafik kazası sonucu bir devlet hastanesinin acil ünitesine müracaat eder, muayenesinde oksipital bölgedeki 12 cm'lik yarasına sütür atılır, pelvis kırığı teşhis edilir. Geldiği andaki vital bulguları stabildir. Bütün konsültasyonları yapıldıktan sonra Ortopedi ve Travmatoloji uzmanının taburcu olabilir yazısıyla hasta acilden evine yollanır. Hasta 4 gün sonra evinde exitus olur. 
Yapılan otopsisinde pelvis ve kafa travmasına bağlı exitus olarak rapor edilir. Bu olguda;

- Pelvis kırıklarının yatırılarak takip edilmesi gerekmektedir.

- Otopsi raporunda mesanede 300-400 cc hematom görüldüğü belirtilen hastanın hem değerlendirmesinin hem de takibinin eksik ve yanlış yapıldığı anlaşılmaktadır.

\section{Alçı uygulamalarına bağglı durumlar}

Çok problemli bir alan da hala alçı uygulamalarıdır. Birçok hastane alçı teknisyeni statüsünde personel çalıştırmaktadır. Bu nedenle artık hekimler alçı sarmamakta ve alçı uygulamaları alçı teknisyenlerine bırakılmaktadır. Alçı teknisyeninin alçı sarmasının yanlış olduğunu iddia edemeyiz. Buradaki problem genellikle; hekimin röntgen kontrolü dışında hiçbir şekilde alçı uygulama prosedürlerine dâhil olmaması, tecrübeli personel ile acemi personel arasındaki farklara dikkat etmemesi, alçı sonrası dolaşım takibini de çoğunlukla alçı teknisyenlerine bırakmasından kaynaklanmaktadır. Halen adli tıp dosyaları arasında kötü ve yanlış alçı uygulamalarına bağlı büyük kentteki hastanelerden taşra hastanelerine kadar azımsanmayacak kadar dosya mevcuttur. Maalesef hekimlerimiz alçı uygulamasına nezaret etmedikleri gibi, alçıdaki ekstremitenin son kontrol ve muayenesini yapmamakta, alçıya bağlı kompartman sendromu belirtileri ile gelen hastaların alçılarının gevşetilmesi görevini bile alçı teknisyenlerine bırakmakta, yeterince gevşetilip gevşetilmediğini kontrol etmemekte, yatırılarak müşahede altına alınıp ekstremitenin rahatlamasını izlememektedirler. Sonuçta Wolkmann kontraktürü ve açık kırıklarda gazlı gangren halen dava dosyalarında bir problem olarak devam etmektedir.

Örnek Olgu 1: Altı yaşında kız çocuğu, büyük bir kentimizin büyük bir eğitim araştırma hastanesine ön kol kapalı çift kırı̆ı̆ nedeniyle müracaat eder. Hastaya kapalı redüksiyon ve alçı uygulaması yapılır, ardından takip ve kontrollere çağırılır. Hastada 4. gün kompartman sendromu ve devamında Wolkmann iskemik kontraktürü gelişir. Bu olguda;

- Alçının önce ön kol kısmının sarıldığı, bu sarılan kısmın ön kol 1/3 proksimal kısmına baskı yaptığı ve onun üzerine ikinci bir kat alçı sarılarak dirsek üstüne çıkıldığı röntgenlerde açıkça görülmüştür.

- Bu hatalı alçı uygulaması maalesef hiçbir asistan veya uzman hekim tarafindan takiplerde fark edilmediği gibi, hasta bu şekilde eve yollanmıştır. Daha sonraki günlerde de takibi yeterli şekilde yapılmadığından hatalı alçı uygulamasına bağlı komplikasyonlar ortaya çıkmıştır.

\section{El ve ekstremite kesiklerinin ve yabancı cisim retansiyonlarının tanı ve yönetimi}

Çoğunlukla el ve ekstremite kesileri muayene edilmeden, röntgen çekilmeden, acil teknisyenlerine "şuraya bir sütur at" talimatı verilerek herhangi bir tendon damar sinir yaralanması olup olmadığına dair bir kayıt konulmadan ve hastanın koopere olup olmadığına dair bilgi verilmeden gönderilmektedir. Daha sonraki muayenelerde özellikle elde tendon ve sinir kesisi olduğu anlaşılan hastalar ilk tedavi eden hekimi ve kurumu şikâyet etmektedirler. Aslında hekim hastanın ilk müracaatında tendon tamirini veya sinir tamirini neden yapmadığı konusunda sorgulanmamaktadır. Hekimin bunu gördüğü anda yapmaması da kusur değildir ancak hekim tendon, damar ve sinir muayenesi yapıp bir patoloji olduğunu veya olmadığını belirledikten sonra hastayı tedavisi için yönlendirdiği takdirde kusurdan muaf olacaktır. Ancak çoğunlukla hekimler hastayı muayene etmemekte, muayene etse de muayene kaydı koymamakta, bu durumda da daha sonra fark edilen patolojilerden dolayı kusurlu duruma düşmektedirler. Bir diğer yaygın durum cam kesileri sonucu yara içinde kalan cam parçaları veya iğne batmalarıdır. Yara içinde kalan cam parçacıkları çekilecek iki yönlü röntgende yüksek oranda görülebilmesine rağmen, çoğunlukla karşılaştığımız dava dosyalarında hastalara hiçbir şekilde röntgen çektirilmediği, hatta iğne batmalarında bile hasta dosyalarında ve hastane verilerinde bir röntgen veya röntgen istemi yapıldığına dair belge bulunmamaktadır. Bu durumda tedavide ilk müdahaleyi yapan hekim ve sağlık ekibi kusurlu duruma düşmektedir.

Örnek Olgu 1: Yirmi yedi yaşında bayan hasta bastığı cam sehpanın kırılması sonucu uyluğunun ön tarafında kesi oluşup cam parçaları girdiği ifadesiyle acil ünitesine başvurur. Yara yıkanır, görülen parçalar çıkarilır ve yaraya dikiş atılır. Aradan 3 ay geçtikten sonra başka bir hastanede yaradan $7 \mathrm{~cm}$ 'lik cam parçası çıkarılır. Bu olguda;

- Konvansiyonel bir radyolojik tetkikte kalan cam parçası görülebilecekken acil başvurusu esnasında hiçbir şekilde hastaya radyolojik tetkik yapılmamıştır.

Tendon kesileri ile ilgili çok sayıda olgu bulunmaktadır; avuç içi kesilerinde acil kliniklerinde görevli hekimler tendon muayenesi yapmamakta veya yapılamadığına dair bir kayıt ve bilgi yazmamakta veya hastayı muayene olması için bir el ve mikrocerrahisi uzmanına yönlendirme yapmamaktadırlar. Bu durumlarda da hekim kusurlu atfedilmektedir. 


\section{Artroskopik girişimler ile ilgili problemler}

Artroskopik girişimlerdeki problemler; yanlış taraf cerrahisinden, yapılan artroskopik rekonstrüksiyon, bağ onarımı ve menisektomi işlemlerinden fayda görmemekten, artroskopik işlem sırasında eklem içinde kırılan enstrüman parçalarına kadar değiş̧en bir yelpazede olmaktadır. Bu nedenle cerrahi sonrası gelişen komplikasyonlarda hastalar tarafından şikâyete neden olmaktadır. Yanlış taraf cerrahisi ile ilgili Sağlık Bakanlığı'nın prosedürleri oldukça iyidir, buna rağmen bu prosedürler uygulanmamakta, taraf işareti uygun şekilde konulmamakta, ameliyata başlamadan önce yapılması gereken time-out (güvenli cerrahi uygulama prosedürleri) çoğunlukla uygulanmamaktadır. Bu da çoğunlukla yanlış taraf cerrahisi ile sonuçlanmaktadır. Yapılan cerrahi işlemden fayda görmemek konusu ise, bütün diğer başlıklarda da geçerli olan, hastanın tedavi ve tedavi sonucu ile ilgili yeterince bilgilendirilmemesinden kaynaklanmaktadır. Hastalar genellikle menisküs ve çapraz bağ patolojileri ile birlikte olan kıkırdak yaralanmaları konusunda bilgilendirilmemekte veya anlayabilecekleri şekilde açıklamaların yapılmamasından kaynaklı yüksek beklenti içerisine girmektedirler. Bunun sonucunda yeterince geçmeyen ağrı ve şikayetlerden hekimin uyguladığı tedavinin yanlış olduğu sonucunu çıkarmaktadırlar. Bu durumu hastanın muayene için gittiği başka cerrahların sözleri ve ifadeleri de büyük ölçüde tetiklemektedir. Artroskopik girişimler esnasında bazen enstrüman uçları kırılmakta, hekimler bu durumu hastaya söylememekte ve aslında çıkarılması gerekmeyen ve hastaya da zararı olmayan küçük bir enstrüman parçası başka bir hekim tarafından görüldüğünde 'burada parça kalmış' şeklinde ifade edilmekte ve bu durumda hastalar sonuçta hekimi şikayet etmektedirler.

\section{Omurga deformiteleri ve kırıkları}

Omurga deformitelerinin düzeltilmesi ve kırıklarının tedavisindeki problem, genellikle cerrahi esnasında veya cerrahi sonrası gelişen nörolojik sorunlar ve kanamaya bağlı exitus vakalarında yoğunlaşmaktadır. Bugün için standart yaklaşım, deformitelerde spinal kord nöromonitörizasyonunun uygulanması, eğer herhangi bir nedenle yapılamıyorsa uyandırma testi ile nörolojik durumun test edilmesi, herhangi bir komplikasyon varlığında da; yanlış vida uygulaması, hematom veyahut aşırı gerginlik ve katlanmaya bağlı spinal kord problemlerinde geri dönüşümü olacak uygun sürede komplikasyonun yönetilmesidir. Büyük damar yaralanmalarında bu durum komplikasyon olarak kabul edilmekte, yaralanmanın erken teşhisi ve komplikasyona uygun şekilde müdahale edilip edilmediği adli tıp tarafindan sorgulanmaktadır.

\section{Kırık Tespiti ve Eklem Protezi Uygulamaları ile ilgili Şikayetler}

Kırık tespitlerinde Ortopedi ve Travmatoloji uzmanlarının en çok dikkat etmesi gereken konu; kırığın cerrahi tedavisinde evrensel olarak kullanılması gereken tespit materyalinin uygun teknikle yapılmasıdır. Uygun tespit materyali uygun teknik ile uygulanmışsa tespit kaybı ve pseudoartroz (kaynamama) çoğunlukla kusur olarak kabul edilmemektedir. Protez uygulamalarında özellikle şikayetler kalça protezlerinde yoğunlaşmakta, diz protezinde daha ziyade cerrahi endikasyonun doğru olup olmadığı konusunda adli tıpa müracaatlar yapılmaktadır. Kalça protezinde uzunluk kısalık farkları, siyatik sinir yaralanması ve femoral arter yaralanması daha çok şikayet konusu olmaktadır. Bu durumlarda hastanın ameliyat öncesi yeterince bilgilendirilmesi önemlidir. Özellikle displazik ve yüksekte kalçalarda, asetabuler parçanın vidalanması esnasında büyük damar yaralanmasına bağlı exitus olguları da şikayet konusu olmaktadır. Bu nedenle zor vakaların deneyimli ekip tarafindan yapılması ve damar yaralanması ile ilgili anestezi ve reanimasyon ekibi ile diyalog önemlidir.

Örnek Olgu 1: Elli yaşında bayan hastanın yüksekte kalça çıkı̆̆ı nedeniyle 2. revizyon ameliyatında yerleştirilen protezde 6-8 ay sonra stem kırığı gelişir. Bunun üzerine cerrahi ekip kırık protezi üretici firması kanalıyla teknik üniversiteye incelemeye yollar. Teknik üniversite protezin üretimle ilgili yapısal bir hata içermediğini, protez kırı̆ı̆ının ameliyat tekniği ile olabileceğini rapor eder. Bu olguda;

- Yükssekte kalça çıkığı ve revizyon cerrahisi sonrası bu tür komplikasyonların gelişme ihtimali yüksektir. Bu olgudaki cerrahi ekip komplikasyon ve komplikasyon yönetiminde eksiksiz davranmıştır ancak bu tür talep ve isteklerde dikkatli olunması gerekmektedir. Teknik üniversiteye stem kırı̆̆ının neden olabileceği yönünde bir soru sorulmadığı halde "yapısal bir hata tespit edilmemiştir" cümlesi ile yetinecekken ne yazık ki teknik üniversite ameliyat tekniğini sorumlu tutan bir ifadede bulunmuştur. Bu olgudaki hekimlerde kusur olmasa bile bu durumların olabileceği göz önünde tutularak, hem hasta hem de başka disiplinler yeterince bilgilendirilmelidir.

\section{Komplikasyonlar ve Komplikasyon Yönetimi}

Komplikasyon yönetiminin ilk ve en önemli aşaması bilgilendirme ve onam formudur. Maalesef bugün hastalarımızın teşhis ve tedavi süreçleri ile ilgili bilgilendirmelerinde ve onamlarda ciddi problemler vardır. Yeterince iyi bir şekilde bilgilendiren ve her aşamada ilgisi hasta tarafindan hissedilen hekimlerle ilgili şikâyet 
olmamaktadır. Bilgilendirme ve ilgi eksikliği üzerine komplikasyon da eklenince problemli durumlar meydana gelmektedir. Bir Ortopedi ve Travmatoloji uzmanı tedavi sürecinde gelişen damar sinir yaralanmaları, kaynamamalar, eklem çıkıkları, hematom oluşumu, enfeksiyon gelişimi gibi süreçlerde; hem hastayı bilgilendirdiği hem de evrensel takip ve uygulama süreçlerini izlediği takdirde, hekim gelişen komplikasyonları yeterli bir şekilde yönetmiştir kararına varılmaktadır. Bu süreçlerde bir eksiklik olursa hekim komplikasyonu yönetememiştir ve kusurludur denilmektedir.

\section{SONUÇ}

Yukarıda özetlediğimiz ve son üç yılda karşılaştığımız Ortopedi ve Travmatoloji branş alanı ile ilgili adli tıp dosyalarının bize sağladığı deneyimler çerçevesinde;

1. Hekim hastayı teşhis ve tedavisinde mutlak bilgilendirmeli ve yapacağı uygulamalarla ilgili açık rızasını (aydınlatılmış onamını) almalıdır.

2. Hekim hastayı mutlaka kendisi değerlendirmeli ve takip etmelidir, tedavi süreçlerinin içinde olmalıdır.
3. Hekim hastayı görmeden whatsapp görüntüsü veya telefondan aldığı bilgilerle hastanın tedavisini ve takibini yönlendirmemelidir.

4. Hekim kendi alanı dışındaki konularda mutlaka gerekli konsültasyonları istemeli ve takip etmelidir.

5. Cerrahi tedavi uygulanmış hastanın takiplerini hekim mutlaka kendisi yapmalıdır.

6. Özellikle büyük damar yaralanması (popliteal arter, femoral arter ve ven) ve kanamalı kırıklarda mortalite riskini düşürerek hastayı multidisipliner yönetmelidir.

7. Alçı uygulaması ve takibini mutlaka ciddiyetle yapmalıdır.

\section{KAYNAKLAR}

1. Adli Tıp Kurumu Kanunu. http://www.atk.gov.tr/mevzuatveri-tabani.html\#tuzukler Erişim tarihi: 01 Kasım 2019.

2. Hekimlik Meslek Etiği Kuralları. https://www.ttb.org.tr/ kutuphane/h_etikkural.pdf Erişim tarihi: 01 Kasım 2019. 